\title{
Qualidade microbiológica da cebolinha (Allium schoenoprasum L.) produzida em hortas comunitárias de Teresina-PI
}

\author{
Microbiological quality of chives (Allium schoenoprasum L.) produced in community gardens in Teresina-PI \\ Calidad microbiológica de la cebolla (Allium schoenoprasum L.) producida en huertas comunitarios de Teresina-PI \\ Laiana Ferreira de CARVALHO ${ }^{1}$ \\ Gleyson Moura dos SANTOS ${ }^{2}$ \\ Clélia de Moura Fé CAMPOS $\mathbf{C A}^{3}$ \\ ${ }^{I}$ Nutricionista, Residente no Programa de Residência Multiprofissional em Saúde do Hospital Universitário da Universidade Federal do Piauí (HU/UFPI), \\ 64049-550 Teresina - PI, Brasil \\ ${ }^{2}$ Nutricionista, Mestre em Ciências e Saúde (PPGCS/UFPI), Pós-Graduando em Fitoterapia Aplicada à Nutrição (UCAM), Doutorando em Alimentos e Nutrição (UFPI), \\ 64049-550 Teresina - PI, Brasil \\ Professora do Departamento de Nutrição. Universidade Federal do Piauí (UFPI), 64049-550 Teresina - PI, Brasil
}

\begin{abstract}
Resumo
As hortaliças constituem uma importante fonte de vitaminas, sais minerais e fibras alimentares, além de possuírem baixo valor calórico, auxiliando para o alcance de uma dieta equilibrada. No entanto, por serem consumidas in natura, não passando por nenhum processamento pós-colheita, são consideradas um dos principais veículos de transmissão de doenças de origem alimentar. O objetivo deste trabalho foi avaliar a qualidade microbiológica da cebolinha produzida em hortas comunitárias no município de Teresina, Piauí. As amostras de cebolinha foram coletadas em hortas comunitárias distribuídas na zona Norte da cidade de Teresina e avaliadas quanto à presença de bactérias aeróbias mesófilas, coliformes totais e termotolerantes. A análise dos dados foi realizada com base na RDC n. 12, de 2 de janeiro de 2001, da Agência Nacional de Vigilância Sanitária (ANVISA). Os resultados obtidos demostraram que, 100\% das amostras de cebolinha analisadas foram consideradas próprias para consumo, apresentando níveis de micro-organismos indicadores de contaminação dentro dos padrões microbiológicos estabelecidos. Apesar destes resultados, foram observados durante a realização desta pesquisa fatores importantes referentes às condições das hortas avaliadas, como uso de adubo orgânico não tratado nas hortaliças e armazenamento inadequado da água usada para irrigação e higienização prévia. Portanto, reforça-se a necessidade da conscientização da população sobre a importância da adequada higienização de hortaliças frescas antes do consumo.
\end{abstract}

Descritores: Segurança Alimentar e Nutricional; Microbiologia de Alimentos; Saúde Pública.

\begin{abstract}
Vegetables are an important source of vitamins, minerals and dietary fiber, besides having low caloric value, helping to reach a balanced diet. However, because they are consumed in natura, not under any post-harvest processing, they are considered one of the main vehicles of transmission of food-borne diseases. The objective of this work was to evaluate the microbiological quality of chives grown in community gardens in the city of Teresina, Piauí. The chives samples were collected in community gardens distributed in the northern part of the city of Teresina and evaluated for the presence of aerobic mesophilic bacteria, total coliforms and thermotolerant bacteria. Data analysis was performed based on RDC n. 12 of January 2, 2001, of the National Agency of Sanitary Surveillance (ANVISA). The results showed that $100 \%$ of the chive samples analyzed were considered suitable for consumption, presenting levels of microorganisms that indicate contamination within established microbiological standards. In spite of these results, important factors related to the conditions of the gardens were evaluated, such as the use of untreated organic fertilizer in the vegetables and inadequate storage of the water used for irrigation and previous hygiene. Therefore, the need to raise awareness of the importance of proper hygiene of fresh vegetables before consumption is reinforced.
\end{abstract}

Descriptors: Food and Nutritional Security; Food Microbiology; Public Health.

\section{Resumen}

Las hortalizas constituyen una importante fuente de vitaminas, sales minerales y fibras alimentarias, además de poseer bajo valor calórico, ayudando al alcance de una dieta equilibrada. Sin embargo, por ser consumidas in natura, no pasando por ningún procesamiento postcosecha, son consideradas uno de los principales vehículos de transmisión de enfermedades de origen alimentario. El objetivo de este trabajo fue evaluar la calidad microbiológica de la cebolla producida en huertas comunitarias en el municipio de Teresina, Piauí. Las muestras de cebolleta fueron recolectadas en huertos comunales distribuidos en la zona Norte de la ciudad de Teresina y evaluados en cuanto a la presencia de bacterias aerobias mesófilas, coliformes totales y termotolerantes. El análisis de los datos se realizó sobre la base de la RDC n. 12, de 2 de enero de 2001, de la Agencia Nacional de Vigilancia Sanitaria (ANVISA). Los resultados obtenidos demostraron que el 100\% de las muestras de cebolla analizadas fueron consideradas propias para el consumo, presentando niveles de microorganismos indicadores de contaminación dentro de los patrones microbiológicos establecidos. A pesar de estos resultados, se observaron durante la realización de esta investigación factores importantes referentes a las condiciones de las huertas evaluadas, como uso de abono orgánico no tratado en las hortalizas y almacenamiento inadecuado del agua usada para irrigación e higienización previa. Por lo tanto, se refuerza la necesidad de la concientización de la población sobre la importancia de la adecuada higienización de hortalizas frescas antes del consumo.

Descritores: Seguridad Alimentaria y Nutricional; Microbiología de Alimentos; Salud Pública.

\section{INTRODUÇÃO}

A busca por um estilo de vida mais saudável, através da prática regular de atividades físicas e adoção de uma dieta equilibrada, vem sendo estimulada por meio de campanhas em diversos países ${ }^{1}$. Para melhoria da alimentação, a Organização Mundial de Saúde (OMS) recomenda o consumo diário de frutas e hortaliças, devido os grandes benefícios que trazem à saúde, como a prevenção de doenças crônicas não transmissíveis (DCNT) ${ }^{2}$.
As hortaliças constituem uma importante fonte de vitaminas, sais minerais e fibras alimentares, além de possuírem baixo valor calórico, auxiliando para o alcance de uma dieta equilibrada ${ }^{1}$. No entanto, por serem consumidas in natura, não passando por nenhum processamento pós-colheita, são consideradas um dos principais veículos de transmissão de doenças de origem alimentar (DTAs), sendo, portanto, necessário a avaliação das condições 
higiênicas e sanitárias de hortaliças consumidas cruas $^{3,4}$.

No campo da alimentação, a agricultura urbana surge como ferramenta para fortalecimento da segurança alimentar e nutricional, desenvolvendo, de forma sustentável, produtos agrícolas voltados para o autoconsumo ou comercialização, contribuindo, assim, para melhora da nutrição e saúde nas comunidades $^{5}$. Diversos estudos atribuem à agricultura urbana benefícios relacionados à promoção do autocuidado, apropriação de conhecimentos sobre alimentação saudável e incentivo no consumo de frutas e hortaliças ${ }^{5,6}$.

As hortas comunitárias de Teresina foram implantadas pela Prefeitura Municipal com o objetivo de melhorar o padrão alimentar da população carente, assim como gerar emprego e renda ${ }^{7}$. A cebolinha (Allium schoenoprasum L.) é uma das principais hortaliças cultivadas, sendo bastante utilizada na culinária das regiões Norte e Nordeste. Porém, são escassos os estudos realizados com o objetivo de avaliar as condições higiênico-sanitárias desta hortaliça. Nesse contexto, o objetivo deste trabalho foi avaliar a qualidade microbiológica de cebolinha proveniente de hortas comunitárias no município de Teresina-PI.

\section{MATERIAL E MÉTODO}

Trata-se de estudo transversal experimental analítico, realizado no período de agosto a novembro de 2017. Foram coletadas 12 amostras de cebolinha de forma aleatória, em hortas comunitárias distribuídas na zona norte da cidade de Teresina, Piauí.

Logo após a aquisição, as amostras foram conduzidas sob refrigeração ao Laboratório de Microbiologia de Alimentos pertencente ao Núcleo de Estudos, Pesquisas e Processamento de Alimentos (NUEPPA) da Universidade Federal do Piauí. Em seguida, foram avaliadas quanto à presença de bactérias aeróbias mesófilas, coliformes totais e termotolerantes.

As análises foram realizadas segundo a metodologia descrita por Silva et al. ${ }^{8}$. Foram utilizadas alíquotas de $25 \mathrm{~g}$ de amostra de cebolinha homogeneizadas assepticamente em $225 \mathrm{~mL}$ de água peptonada $0,1 \%$, obtendo-se a diluição $10^{-1} \mathrm{e}$ subsequentes diluições, $10^{-2}$ e $10^{-3}$. A partir dessas diluições foram quantificadas as análises de coliformes termotolerantes e micro-organismos aeróbios mesófilos.

\section{- Contagem de micro-organismos aeróbios mesófilos}

Para a contagem de micro-organismos aeróbios mesófilos, foi utilizado o método de semeadura em profundidade.

Selecionaram-se três diluições da amostra para inoculação de $1,0 \mathrm{~mL}$ de cada diluição em placas de Petri estéreis e vazias. Em seguida, foi vertido 20ml de Ágar Padrão para Contagem (PCA), previamente fundido e resfriado a $45^{\circ} \mathrm{C}$. O inóculo foi então misturado com o meio de cultura em movimentos circulares suaves, 10 vezes no sentido horário e 10 vezes no sentido anti-horário. Após a completa solidificação do meio, as placas foram invertidas e incubadas a $35^{\circ} \mathrm{C}$ por $48 \mathrm{~h}$.

Para a contagem das colônias formadas e cálculo dos resultados, foram selecionadas as placas com 25 a 250 colônias, contando-as em um contador de colônias. O número de unidades formadoras de colônia (UFC) por grama da amostra foi calculado através da multiplicação do número de colônias pelo inverso da diluição inoculada (UFC/g = número de colônias/diluição).

A legislação não prevê limites para a contagem de aeróbios mesófilos em hortaliças in natura, portanto utilizou-se a recomendação de Morton $^{9}$, para contagem de micro-organismos aeróbios mesófilos em vegetais congelados e similares.

\section{- Contagem de Coliformes totais e termotolerantes}

A análise de coliformes totais e termotolerantes foi realizada pelo método do Número Mais Provável (NMP).

Para o teste presuntivo, utilizou-se tubos contendo Caldo Lauril Sulfato Triptose (LST) com tubos de Durhan invertidos, adicionando $1 \mathrm{~mL}$ da diluição por tubo com $10 \mathrm{~mL}$ de LST. Os tubos foram incubados a $35^{\circ} \mathrm{C}$ por $24-48 \mathrm{~h}$. Para o teste confirmativo, transferiu-se uma alçada de cada tubo positivo de LST para tubos com Caldo Verde Brilhante (VB). Os tubos foram incubados a $35^{\circ} \mathrm{C}$ por 24-48h. Para os tubos com formação de gás, a confirmação de coliformes termotolerantes foi realizada através da repicagem em Caldo E. coli (EC), com incubação em banho-maria por 24 horas a $45^{\circ} \mathrm{C}$.

Após o período de incubação, determinou-se o NMP por grama para cada tubo positivo, consultando-se a tabela de Hoskins.

A análise dos dados foi realizada com base na RDC n. 12, de 2 de janeiro de 2001, da Agência Nacional de Vigilância Sanitária (ANVISA), a qual prevê os níveis aceitáveis de coliformes termotolerantes para hortaliças frescas, in natura, preparadas para consumo direto ${ }^{10}$.

\section{RESULTADOS E DISCUSSÃO}

Os resultados obtidos mediante as análises realizadas para micro-organismos aeróbios mesófilos, coliformes totais e termotolerantes estão representados na Tabela 1.

Para as análises de bactérias aeróbias mesófilas, os resultados variaram de $1,1 \times 10^{3}$ a 5,7 x $10^{1}$ a UFC/g. Valores estes de acordo com a recomendação de Morton ${ }^{9}$, a qual estabelece valores 
máximos entre $10^{5}$ a $10^{6} \mathrm{UFC} / \mathrm{g}$ para contagem de micro-organismos aeróbios mesófilos em vegetais congelados e similares.

Coutinho et al. $^{3}$ encontraram valores semelhantes em alfaces comercializadas em feiras livres no município de Sobral- CE, com média de 3,2 x $10^{5} \mathrm{UFC} / \mathrm{g}$. Já nos trabalhos realizados por Maffei ${ }^{12}$ e França, Bonnas e Silva ${ }^{13}$, as contagens de aeróbios mesófilos em diversas hortaliças folhosas foram superiores a $10^{6} \mathrm{UFC} / \mathrm{g}$.

Segundo Franco e Landgraf ${ }^{14}$, alimentos com contagens superiores a $10^{6}$ indicam que o produto apresenta alterações sensoriais, além de representar risco à saúde do consumidor, uma vez que todas as bactérias patogênicas de origem alimentar são mesófilas. Portanto, nenhuma das amostras apresentou padrões insatisfatórios quanto às contagens de aeróbios mesófilos.

Coliformes totais estiveram presentes em contagens de contagens iguais ou inferiores a 2,4 $\mathrm{x}$ $10^{3} \mathrm{NMP} / \mathrm{g}$. A legislação não prevê limites para níveis de coliformes totais, entretanto, preconiza-se que contagens na ordem de $10^{5}-10^{6} \mathrm{NMP} / \mathrm{g}$ indicam alterações sensoriais no produto, além de perda do valor nutricional e presença de patógenos, tornando-o impróprio para consumo humano ${ }^{11}$. Fato este que favorece os resultados obtidos neste estudo, tendo em vista, que na ordem de $10^{5}-10^{6} \mathrm{NMP} / \mathrm{g}$ não foram observados presença destes micro-organismos.

Estes resultados corroboram com os dados obtidos por Silveira, Silva e Pessoa ${ }^{4}$, cujas análises revelaram contagens entre $\leq 3$ e $2,4 \times 10^{3} \mathrm{NMP} / \mathrm{g}$ de coliformes totais em amostras de alface provenientes de hortas comunitárias de Teresina.

Para as análises de coliformes termotolerantes, os resultados apresentados revelam que, das 12 amostras analisadas, $100 \%$ foram consideradas próprias para consumo, considerando a resolução $\mathrm{RDC} \mathrm{n}^{\circ} 12 / 2001$, que estabelece o limite máximo de $10^{2} \mathrm{NMP} / \mathrm{g}$ de coliformes termotolerantes para hortaliças frescas, in natura ${ }^{10}$.

Em discordância com os resultados obtidos nesta pesquisa, diferentes estudos realizados por Oliveira et al. ${ }^{15}$, Silva et al. ${ }^{16}$ e Bezerra ${ }^{11}$, indicaram contagens elevadas de coliformes termotolerantes em amostras de vegetais folhosos, como alface, rúcula e coentro, comercializados em hortas e feiras livres.

De acordo com Silva ${ }^{17}$, o grau de contaminação em uma hortaliça pode sofrer influência de sua estrutura, sendo que, as que contêm folhas múltiplas e, por consequência, grande área de contato, são mais susceptíveis à contaminação. A cebolinha é uma aliácea, suas folhas são cilíndricas, inteiras, basais, com pelos simples $^{18}$, tais características propiciam menor superfície de contato para aderência de micro-organismos em suas folhas.

Uma possível explicação para os resultados verificados no presente estudo é a presença de compostos dialil sulfitos nos membros da família Alliaceae, como a cebolinha. Acredita-se que estes compostos conferem propriedades antimicrobianas às plantas desta família; a presença de tais compostos pode ter contribuído para a baixa contaminação encontrada na cebolinha. Um estudo realizado por Rattanachaikunopon e Phumkhachorn ${ }^{19}$ mostrou que os compostos dialil sulfitos presentes na cebolinha foram capazes de inibir bactérias patogênicas, como Escherichia coli O157:H7, Salmonella enterica e Staphylococcus aureus.

Ressalta-se que uma das limitações deste estudo é o tamanho da amostra, que limitou as possíveis inferências estatísticas. Acredita-se que uma amostragem maior permitiria uma avaliação quantitativa adequada. Por outro lado, a carência de estudos sobre o tema reforça a importância deste estudo como referência para pesquisas futuras.

Tabela 1. Ocorrência de micro-organismos aeróbios mesófilos, coliformes totais e termotolerantes em amostras de cebolinha produzidas em hortas comunitárias de Teresina-PI, 2017

\begin{tabular}{|c|c|c|c|}
\hline \multirow[b]{2}{*}{ Amostras } & \multirow{2}{*}{$\begin{array}{c}\text { Micro- } \\
\text { organismos } \\
\text { aeróbios } \\
\text { mesófilos } \\
\text { (UFC/g) }\end{array}$} & \multicolumn{2}{|c|}{ Coliformes } \\
\hline & & $\begin{array}{l}\text { Totais } \\
(\mathrm{NMP} / \mathrm{g})\end{array}$ & $\begin{array}{c}\text { Termotolerantes } \\
\text { (NMP/g) }\end{array}$ \\
\hline $\mathbf{A}$ & $1,0 \times 10^{3}$ & $4,6 \times 10^{2}$ & 29 \\
\hline B & $5,7 \times 10^{1}$ & $2,1 \times 10^{2}$ & 15 \\
\hline $\mathbf{C}$ & $3,8 \times 10^{4}$ & $1,1 \times 10^{3}$ & $\leq 3$ \\
\hline D & $4,7 \times 10^{5}$ & 93 & 15 \\
\hline $\mathbf{E}$ & $2 \times 10^{5}$ & $\geq 1,1 \times 10^{3}$ & 20 \\
\hline $\mathbf{F}$ & $3,2 \times 10^{5}$ & $2,4 \times 10^{2}$ & 29 \\
\hline $\mathbf{G}$ & $8,5 \times 10^{4}$ & 23 & $\leq 3$ \\
\hline $\mathbf{H}$ & $7,7 \times 10^{4}$ & $\leq 3$ & $\leq 3$ \\
\hline I & $2,9 \times 10^{5}$ & 28 & $\leq 3$ \\
\hline $\mathbf{J}$ & $1,1 \times 10^{4}$ & 93 & 15 \\
\hline $\mathbf{K}$ & $1,1 \times 10^{4}$ & 28 & $\leq 3$ \\
\hline L & $1,1 \times 10^{5}$ & $2,4 \times 10^{3}$ & 20 \\
\hline Padrão & $10^{6}-10^{7 a}$ & $10^{6}-10^{7 b}$ & $10^{2 \mathrm{c}}$ \\
\hline
\end{tabular}

Legenda: ${ }^{\mathrm{a}}$ Morton $(2001)^{9} ;{ }^{\mathrm{b}}$ Bezerra $(2015)^{11}$; ${ }^{\mathrm{c}}$ Resolução RDC n ${ }^{\mathrm{o}} 12$ (BRASIL, 2001) ${ }^{10}$ Fonte: Dados da pesquisa

\section{CONCLUSÃO}

Os resultados obtidos demostraram que a cebolinha produzida nas hortas comunitárias de Teresina-PI apresenta níveis de micro-organismos indicadores de contaminação dentro dos limites máximos permitidos pelos padrões estabelecidos na legislação brasileira. Entretanto, reforça-se a necessidade da conscientização da população sobre a importância da adequada higienização de hortaliças frescas antes do consumo, frente à constante elucidação de envolvimento de produtos desta natureza com surtos de doenças de origem alimentar.

\section{REFERÊNCIAS}

1. Gomes TS. Pesquisa de Salmonella spp, Escherichia coli e Staphylococcus aureus em amostras de alface e água de coco comercializadas em Campina Grande-PB [monografia]. Campina Grande: Universidade Estadual da Paraíba UEPB; 2015.

2. World Health Organization. Fruit and vegetable promotion initiative: report of the meeting; August 2003. Geneva: WHO; 2003.

3. Coutinho MGS, Ferreira CF, Neves AM, Alves 
FRL, Souza FFP, Fontenelle FOS. Avaliação microbiológica e parasitológica de alfaces (Lactuca sativa L.) comercializadas em feiras livres no município de Sobral-CE. Rev UninCor. 2015;13(2):388-97.

4. Silveira SL, Silva VAM, Pessoa MLSB. Análise microbiológica de alfaces (Lactuca sativa $\mathrm{L}$.) produzidas em hortas comunitárias de TeresinaPI. Hig Aliment. 2015;29(248/249):84-87.

5. Costa CGA, Garcia MT, Ribeiro SM, Salandini MFS, Bógus CM. Hortas comunitárias como atividade promotora de saúde: uma experiência em Unidades Básicas de Saúde. Ciênc saúde coletiva. 2015;20(10):3099-110.

6. Al-Delaimy WK, Webb M. Community gardens as environmental health interventions benefits versus potential risks. Curr Environ Health Rep. 2017;4(2):252-65.

7. Monteiro JPR. Hortas comunitárias de Teresina: agricultura urbana e perspectiva de desenvolvimento local. Revista Iberoamericana Economia Ecol. 2006;5(1):47-60.

8. Silva N, Junqueira VCA, Silveira NFA, Taniwaki MH, Gomes RAR, Ozaki MM. Manual de Métodos de Análise Microbiológica de Alimentos. São Paulo: Varela, 2010.

9. Morton RD. Aerobic Plate Count. In: Downes FP, Ito K. (Eds). Compendium of Methods for the Microbiological Examination of Foods. Washington:Apha, 2001.

10.Brasil. Resolução RDC n ${ }^{\circ} 12$, de 02 de janeiro de 2001. Regulamento técnico sobre os padrões microbiológicos em alimentos. Diário Oficial da República Federativa do Brasil, Brasília, DF, 10 jan. 2001.

11.Bezerra NS. Pesquisa de Salmonella spp. e microorganismos indicadores higiênicossanitários em hortaliças comercializadas em estabelecimento formal e não formal de João Pessoa- PB [monografia]. João Pessoa: Universidade Federal da Paraíba - UFPB; 2015.

12.Maffei DF. Qualidade higiênico-sanitária de hortaliças produzidas pelos sistemas de cultivo orgânico e convencional, comercializadas na cidade de Araraquara-SP [dissertação]. Araraquara: Faculdade de Ciências Farmacêuticas de Araraquara - UNESP, Araraquara; 2012.

13.França BR, Bonnas DS, Silva CM. Qualidade higiênicossanitária de alfaces (Lactuca sativa L.) comercializadas em feiras livres na cidade de Uberlândia-MG, Brasil. Biosci J. 2014; 30(1):458-66.

14.Franco BDG, Landgraf M. Microbiologia dos alimentos. São Paulo: Atheneu; 2008.

15. Oliveira AS, Almeida AG, Sgrignolli LA, Otoboni AMMB, Tanaka AY, Dorta C et al. Levantamento microbiológico da alface (Lactuca sativa L.) produzida em hortas da cidade de Marília-SP. Hig Aliment. 2013;27(224/225):90-94.

16. Silva AS, Silva IMM, Rebouças LT, Amor ALM. Análise parasitológica e microbiológica de hortaliças comercializadas no município de Santo Antônio de Jesus, Bahia (Brasil). Vig Sanit Debate. 2016;4(3):77-85.

17.Silva JS. Adubação orgânica de alface: contaminação microbiológica e desenvolvimento da cultura, aspectos químicos e biológicos do solo [monografia] - Londrina: Universidade Tecnológica Federal do Paraná - UFPR; 2015.

18. Oliveira DM, Novaes BCB, Lucena VB, Souza TS, Barros NCL, Dias SS et al. Perfil parasitológico do cheiro verde comercializado em feiras livres de imperatriz- MA. Biota Amazônia. 2016;6(2):123-26.

19.Rattanachaikunopon P, Phumkhachorn, P. Dyallyl sulfide contente and antimicrobial activity against food-borne pathogenic bactéria of chives (Allium schoenoprasum). Biosci Biotechonol Biochem. 2008;72(11):2987-91.

\section{CONFLITO DE INTERESSES}

Os autores declaram não haver conflitos de interesse.

\section{AUTOR PARA CORRESPONDENCIA}

\section{Gleyson Moura dos Santos}

g_leyson_moura@hotmail.com
Submetido em 30/08/2018 Aceito em 04/10/2018 